\title{
Longitudinal assessment in COPD patients: multidimensional variability and outcomes
}

\author{
Ciro Casanova ${ }^{1,2}$, Armando Aguirre-Jaíme², Juan P. de Torres ${ }^{3}$, \\ Victor Pinto-Plata ${ }^{4}$, Rebeca Baz², Jose M. Marin' ${ }^{5}$, Miguel Divo ${ }^{4}$, \\ Elizabeth Cordoba ${ }^{2}$, Santiago Basaldua ${ }^{2}$, Claudia Cote $^{6 \dagger}$ and \\ Bartolomé R. Celli ${ }^{4}$
}

\begin{abstract}
Affiliations: 'Pulmonary Dept, Hospital Universitario La Candelaria, Tenerife, ${ }^{2}$ Pulmonary Research Unit, Hospital Universitario La Candelaria, Tenerife, ${ }^{3}$ Clinica Universidad de Navarra, Pamplona, and ${ }^{5}$ Respiratory Service, Hospital Miguel Servet, Zaragoza, Spain. ${ }^{4}$ Dept of Pulmonary, Critical Care and Sleep Medicine, Harvard Medical School, Brigham and Women's Hospital, Boston, MA, and 'Bay Pines VA Health Care System, St Petersburg, FL, USA.
\end{abstract}

Correspondence: C. Casanova, Respiratory Research Unit, Pulmonary Dept, Hospital Universitario La Candelaria, Carreteradel Rosario 145, 38010 Santa Cruz de Tenerife, Spain. E-mail: casanovacirodamail.com

ABSTRACT The value and timing of multidimensional assessments in chronic obstructive pulmonary disease (COPD) remains unclear because there is little information about their variability and relationship to outcome. The aim of this study was to determine the progression of COPD using clinical and spirometric variability over time with mortality as the outcome.

We determined the annual intra-individual variability of forced expiratory volume in $1 \mathrm{~s}(\mathrm{FEV} 1)$ and BODE (body mass index, airflow obstruction, dyspnoea, exercise capacity) index in 403 patients with at least five measurements. The pattern was defined as "stable" if the annual change remained constant in $\geqslant 66 \%$ of the observations and "unstable" if it did not meet that threshold. We explored the minimum number of yearly observations that related to mortality in the 704 patients of the cohort.

The "unstable" pattern of FEV1 was seen in $53 \%$ and $40 \%$ of patients using a threshold of $40 \mathrm{~mL} \cdot \mathrm{year}^{-1}$ and $100 \mathrm{~mL} \cdot$ year $^{-1}$, respectively. There was a slightly more "stable" pattern in the BODE index (62\% for 1 point). A profile associated with mortality was defined by a baseline measurement followed by annual measurements for 2 years of the BODE index, but not its individual components, including FEV1 $(\mathrm{p}<0.001)$.

Progression of COPD measured using FEV1 is inconsistent and relates poorly to outcome. Monitoring the more stable BODE index better assesses disease progression.

0

@ERSpublications

COPD patients have a high annual variability in FEV1. The BODE index is more stable and useful to assess COPD progression http://ow.ly/rO5T0

For editorial comments see page 665.

Received: June 072013 | Accepted after revision: July 312013 | First published online: Sept 262013

Conflict of interest: None declared.

Copyright @ERS 2014 


\section{Introduction}

Chronic obstructive pulmonary disease (COPD) is one of the leading causes of morbidity and mortality worldwide [1]. COPD is a complex disease and several authors have shown that it is not always progressive, with a high variability among patients [2-5]. These studies have challenged the classical concept of the onedimensional accelerated decline in forced expiratory volume in $1 \mathrm{~s}(\mathrm{FEV} 1)$ as the natural history of patients with COPD [6].

In the studies evaluating lung function, the annual decline has been expressed as a mean value for groups or as a change calculated from individual FEV1 slopes [3]. However, many authors, including FLETCHER and PETO [6], noticed irregular patterns with wide swings in FEV1 that are not expressed in the smoothed data as provided by statistical analyses. There have been no attempts to relate long-term individual variability to clinical consequences in COPD, and it is still unclear with what frequency and over what length of time evaluations to determine the clinical stability of the patients should be planned.

It is possible that the pattern of variability of the dimensions used to determine disease progression may have clinical implications, as shown for restrictive lung physiology in the Tucson Epidemiological Study of Airway Obstructive Disease [7]. In that study, the authors developed a spirometric pattern classification using predefined threshold of variability of FEV1 to express the pattern of lung function change as "consistent" (little variability over time) or "inconsistent" (large variability over time). They observed that patients with an "inconsistent" restrictive pattern had a higher mortality over time than those with a "consistent" (less variability) pattern. If the same was true for COPD, then the monitoring of disease progression has to take this variability into account.

The guidelines, based on expert opinion, suggest that spirometry measurements be performed 1 year apart [1], but do not address the issue of variability and its implications. Furthermore, they do not provide data to support the value of repeated measurements of any other clinical dimension [1].

We hypothesised that in COPD, the longitudinal variability pattern of the body mass index, airway obstruction, dyspnoea, exercise capacity (BODE) index would better predict all-cause mortality compared to variability in FEV1, because BODE incorporates multiple domains of the disease and would vary less over time. To test this hypothesis we applied the analysis developed by GuERRA et al. [7] to the BODE cohort. We calculated the individual variability over time of the FEV 1 and the BODE index and its components, the body mass index (BMI), modified Medical Research Council (mMRC) dyspnoea score and the 6-min walk distance (6MWD). We then related the observed variability pattern of these variables to all-cause mortality.

\section{Methods}

Subjects

A total of 1151 outpatients (1058 males) with COPD in pulmonary clinics in the USA (Bay Pines VA Medical Center, St Petersburg, FL) and Spain (Hospital Universitario La Candelaria, Tenerife), participated in the study. They were evaluated yearly from 1997 until 2009 or until death [8]. The human review board at each centre approved the study and all patients signed the informed consent form.

COPD was defined by a smoking history of $\geqslant 20$ pack-years and a post-bronchodilator FEV1/forced vital capacity ratio $<0.7$. Patients had been stable for $\geqslant 6$ weeks and received optimal medical therapy [9]. Exclusion criteria were uncontrolled comorbidities such as malignancy at baseline, asthma or other confounding diseases that could interfere with the study.

\section{Pulmonary function and clinical variables}

Spirometry, lung volumes and a single-breath diffusing capacity of the lung for carbon monoxide were measured according to American Thoracic Society (ATS) and European Respiratory Society (ERS) guidelines $[10,11]$ and severity of obstruction was classified according to ATS/ERS/Global Initiative for Chronic Obstructive Lung Disease (GOLD) standards [1,9]. The 6MWD was measured as the better of two walks separated by $30 \mathrm{~min}$ [12]. Dyspnoea was evaluated using the mMRC scale [13]. BMI was calculated in $\mathrm{kg} \cdot \mathrm{m}^{-2}$. The BODE index was calculated as previously described [8]. Comorbidities were evaluated using the Charlson index [14]. Hospitalisations and all-cause mortality were recorded [15].

\section{Longitudinal patterns}

To optimally estimate individual longitudinal patterns, at least five annual measurements were required for each dimension. 
Spirometric patterns

Spirometric patterns were generated as follows. 1) The rate of decline in FEV1 using two different thresholds: $<40$ or $\geqslant 40 \mathrm{~mL} \cdot$ year $^{-1}$ and $<100$ or $\geqslant 100 \mathrm{~mL} \cdot$ year $^{-1}$. The selection of the threshold of $40 \mathrm{~mL} \cdot$ year $^{-1}$ was based on the rates described in healthy smokers [16] and that used in the Evaluation of COPD Longitudinally to Identify Predictive Surrogate Endpoints (ECLIPSE) study [2]. We also explored the more conservative threshold of $100 \mathrm{~mL} \cdot$ year $^{-1}$, because this is thought to be the minimally important clinical difference for this variable [17]. 2) Using the thresholds defined above, the variability of the measurement was defined as: "stable" if the annual rate of FEV1 change was observed in $\geqslant 66 \%$ of the measurements, and "unstable" if the annual rate of FEV1 change was observed in $<66 \%$ of measurements. We chose a more stringent threshold of $66 \%$ compared to the $50 \%$ used by GUERRA et al. [7] in order to be more conservative in the definition of the pattern.

To correct for differences in anthropometry and sex, we repeated the analysis using two normalising thresholds of $3 \%$ or $6 \%$ of predicted FEV1. The $3 \%$ value is based on the results of the Lung Health Study as proposed by SANDFORD et al. [18], and the $6 \%$ value was tested to approximate the $100-\mathrm{mL} \cdot \mathrm{year}^{-1}$ threshold defined above.

\section{BODE and its components}

We evaluated the variability of the BODE index using changes of 1 point as the threshold that predicts mortality. To define the "stable" or "unstable" patterns we used the same $66 \%$ threshold values than used for FEV1. We applied the same definition for each of the other BODE components: for BMI a threshold of $1 \mathrm{~kg} \cdot \mathrm{m}^{-2}$, for dyspnoea 1 unit on the mMRC scale and for $6 \mathrm{MWD}$ a cut-off value of $50 \mathrm{~m}$. All these thresholds were based on their validated capacity to predict mortality [19-21].

\section{Monitoring disease progression}

Using patients who had at least a baseline measurement and two yearly follow-up measurements of all variables (three measurements) we then evaluated the minimal number of visits where the presence of a pattern could predict mortality at 12 and 24 months (fig. 1).

\section{Statistical analysis}

Data are summarised as frequencies for categorical variables, mean \pm SD for normally distributed variables and median (5th-95th percentile) for non-normally distributed variables. Comparisons between groups were performed using Pearson's Chi-squared test, the Kruskal-Wallis H-statistic and the Mann-Whitney Utest. We performed a logistic regression analysis to determine how much more the BODE index predicts mortality than 6MWD, since, in contrast to BMI and the mMRC dyspnoea scale, the variability of the $6 \mathrm{MWD}$ did relate to mortality in the univariate analysis. Significance level was established as a $\mathrm{p}<0.05$. Calculations were made using SPSS 20.0 (Chicago, IL, USA).

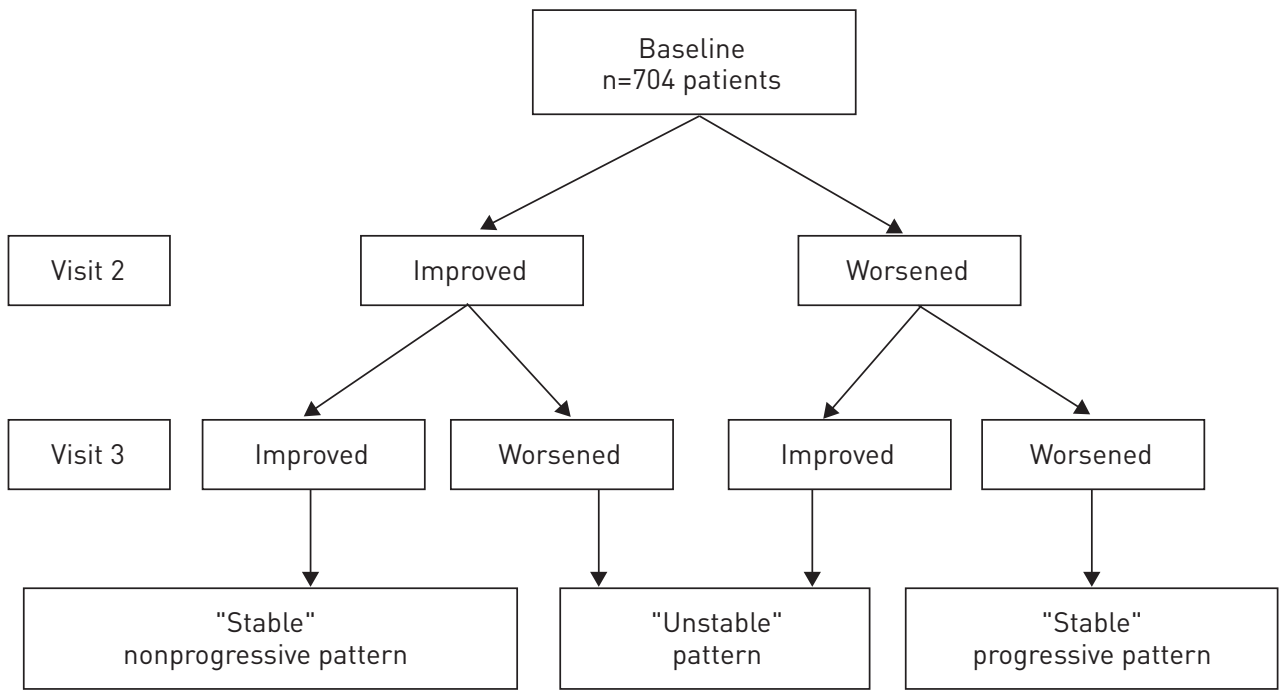

FIGURE 1 Algorithm describing the grouping of patients with chronic obstructive pulmonary disease into patterns of disease progression determined over 2 years related to mortality. Each variable of the BODE (body mass index, airflow obstruction, dyspnoea, exercise capacity) index was analysed using the same methodology (see the Methods section). 
TABLE 1 Baseline characteristics of the patients

COPD patients with $\geqslant 3$ annual measurements
COPD patients with $<3$ annual measurements p-value

\begin{tabular}{|c|c|c|c|}
\hline Subjects & 704 & 447 & \\
\hline Male/female & $652 / 52$ & $406 / 41$ & 0.334 \\
\hline Age years & $66 \pm 9$ & $67 \pm 9$ & 0.103 \\
\hline Smoking pack-years & $66 \pm 26$ & $70 \pm 28$ & 0.393 \\
\hline Active smoking \% & 29 & $\overline{38}$ & 0.004 \\
\hline $\mathrm{BMI} \mathrm{kg} \cdot \mathrm{m}^{-2}$ & $27 \pm 5.6$ & $26.9 \pm 6.2$ & 0.551 \\
\hline FEV $1 \mathrm{~L}$ & $1.41 \pm 0.56$ & $1.39 \pm 0.65$ & 0.467 \\
\hline FEV $1 \%$ & $46 \pm 17$ & $46 \pm 20$ & 0.969 \\
\hline $\mathrm{PaO}_{2} \mathrm{mmHg}$ & $72.7 \pm 11.9$ & $69.6 \pm 14.7$ & $<0.001$ \\
\hline FVC $\%$ & $72 \pm 21$ & $70 \pm 20$ & 0.705 \\
\hline 6MWD m & $372 \pm 127$ & $329 \pm 154$ & $<0.001$ \\
\hline mMRC dyspnoea score & $2(0-4)$ & $2(1-4)$ & 0.015 \\
\hline BODE index & $3(0-8)$ & $4(0-9)$ & 0.002 \\
\hline IC/TLC ratio & $0.30 \pm 0.12$ & $0.29 \pm 0.11$ & 0.958 \\
\hline Kсо \% & $60 \pm 23$ & $58 \pm 21$ & 0.702 \\
\hline Charlson index & $4(2-9)$ & $4(0-11)$ & 0.987 \\
\hline Hospitalisations per patient per year & $0.21 \pm 0.02$ & $0.41 \pm 0.04$ & $<0.001$ \\
\hline Inhaled anticholinergic \% & 68 & 62 & 0.109 \\
\hline Inhaled $\beta_{2}$-agonist $\%$ & 92 & 86 & 0.003 \\
\hline Inhaled corticosteroid \% & 62 & 48 & $<0.001$ \\
\hline SGRQ & $47 \pm 22$ & $50 \pm 22$ & 0.167 \\
\hline
\end{tabular}

Data presented as $\mathrm{n}$, mean \pm SD or median (5-95th percentile). COPD: chronic obstructive pulmonary disease; BMI: body mass index; FEV1: forced expiratory volume in $1 \mathrm{~s} ; \mathrm{PaO}_{2}$ : arterial oxygen tension; FVC: forced vital capacity; 6MWD: 6-min walk distance; mMRC: modified Medical Research Council; BODE: BMI, airflow obstruction, dyspnoea, exercise capacity; IC: inspiratory capacity; TLC: total lung capacity; Kco: transfer coefficient of the lung for carbon monoxide; SGRQ: St George's Respiratory Questionnaire.

\section{Results}

Study population

From the 1151 patients, 403 had at least five lung function measurements. The mean number of measurements was 6.62 (range 5-11). To establish the variability of BODE and its components we used data from 375 patients who had at least five measurements of all variables.

Once the variability pattern was determined for all domains, we re-evaluated in all 704 patients who had at least three measurements (baseline and two visits) and related the impact of the variability to predict mortality. Baseline characteristics of these patients are shown in table 1.

\section{FEV1 pattern}

The proportions of patients with different patterns of FEV1 are shown in table 2. Most of the patients demonstrated a noncontinuous variable pattern (unstable) with increases and decreases in FEV1, but the proportion varied depending on the threshold used. The majority of patients $(214(53 \%))$ had an unstable pattern of lung function, $85(21 \%)$ had a stable pattern of decline $\geqslant 40 \mathrm{~mL} \cdot \mathrm{year}^{-1}$ and $104(26 \%)$ had a stable pattern of decline $<40 \mathrm{~mL} \cdot$ year $^{-1}$. The unstable pattern was still frequent $(40 \%)$ at the higher threshold for FEV1 $\left(100 \mathrm{~mL} \cdot \mathrm{year}^{-1}\right)$. The unstable pattern remained the most frequent when we expressed the variability of the FEV1 as $3 \%$ change, and decreased (26\% of patients) when we used a $6 \%$ threshold.

Random free concordance was low between absolute value $(\mathrm{mL})$ and per cent predicted reference value for low and high values of cut-off points (Cohen's $\kappa 57 \%$ and $51 \%$, respectively).

\section{Pattern of BODE and its components}

Based on the yearly BODE index change (1 point), we observed the following: $33(9 \%)$ patients had a stable worsening of $\geqslant 1$ point, $200(53 \%)$ patients had a stable change of $<1$ point and $142(38 \%)$ patients had an unstable pattern.

The variability of BMI and mMRC dyspnoea scores had little relationship to mortality. Interestingly, there was also variability of the 6MWD; however, a stable decrease of $\geqslant 50 \mathrm{~m} \cdot$ year $^{-1}$ over 2 years was predictive of mortality (table 3). 
TABLE 2 Distribution of annual individual longitudinal pattern of forced expiratory volume in $1 \mathrm{~s}$ (FEV1) estimated over at least five measures and according to different thresholds

\begin{tabular}{|c|c|c|c|c|c|}
\hline & \multicolumn{4}{|c|}{ FEV 1} & \multirow{2}{*}{$\frac{\text { BODE index }}{1 \text { point }}$} \\
\hline & $\geqslant 40 \mathrm{~mL} \cdot$ year $^{-1}$ & $\geqslant 100 \mathrm{~mL} \cdot$ year $^{-1}$ & $3 \%$ & $6 \%$ & \\
\hline Stable nonprogressive & $104(26)$ & $194(48)$ & 133 (33) & 294 (73) & 199 (53) \\
\hline Unstable & 214 (53) & $161(40)$ & $246(61)$ & $105(26)$ & 142 (38) \\
\hline
\end{tabular}

Data are presented as $\mathrm{n}(\%)$. BODE: body mass index, airflow obstruction, dyspnoea, exercise capacity.

TABLE 3 Distribution of patients by cut-off point for the BODE (body mass index, airflow obstruction, dyspnoea, exercise capacityl index and individual components and longitudinal 2-year pattern and mortality after 12 and 24 months

Variable and cut-off point

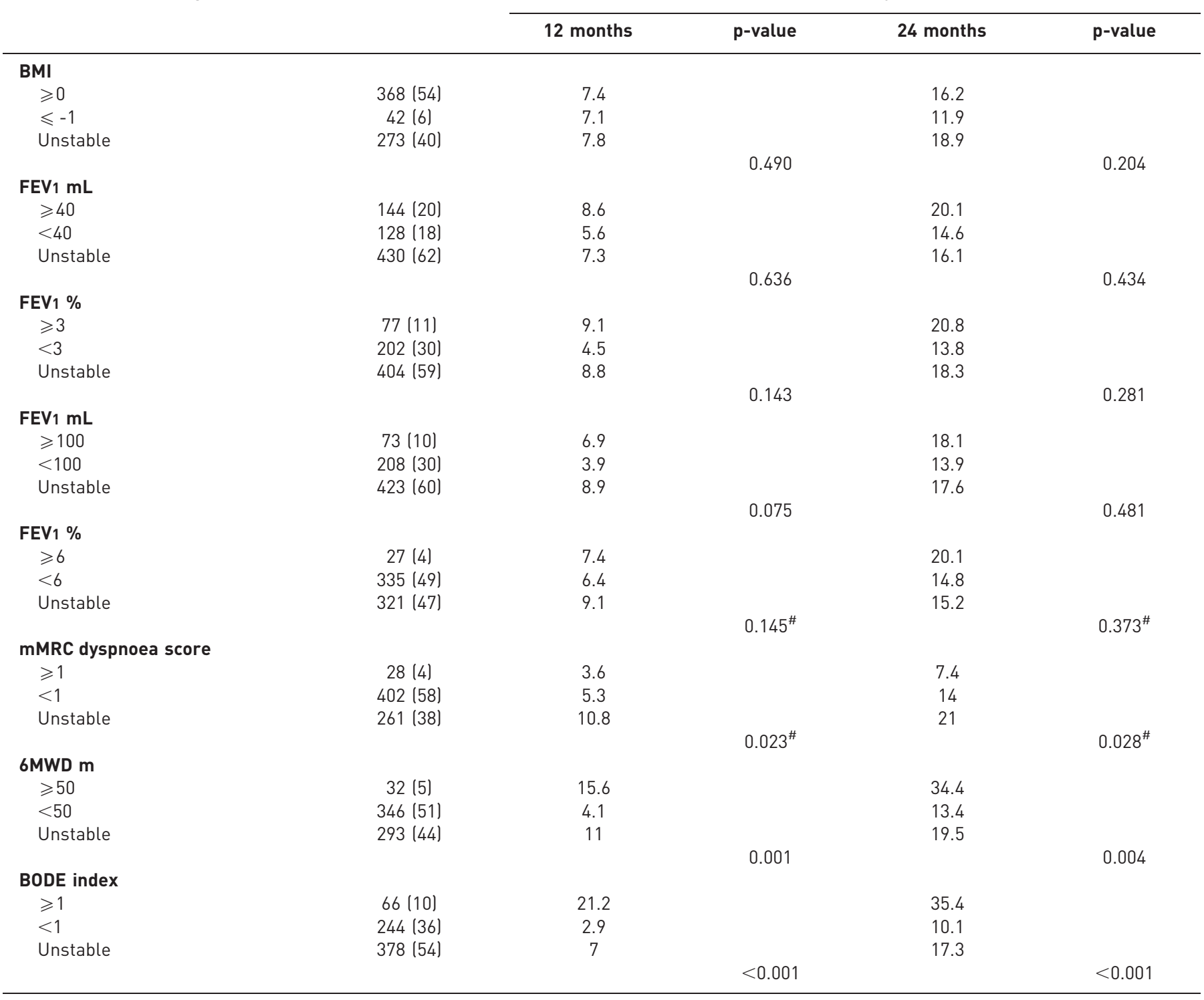

Data are presented as $\mathrm{n}(\%)$ or \%, unless otherwise stated. BMI: body mass index; FEV1: forced expiratory volume in $1 \mathrm{~s}$; mMRC: modified Medical Research Council; 6MWD: 6-min walk distance. ${ }^{\#}$ : number of patients is very low in some patterns. 


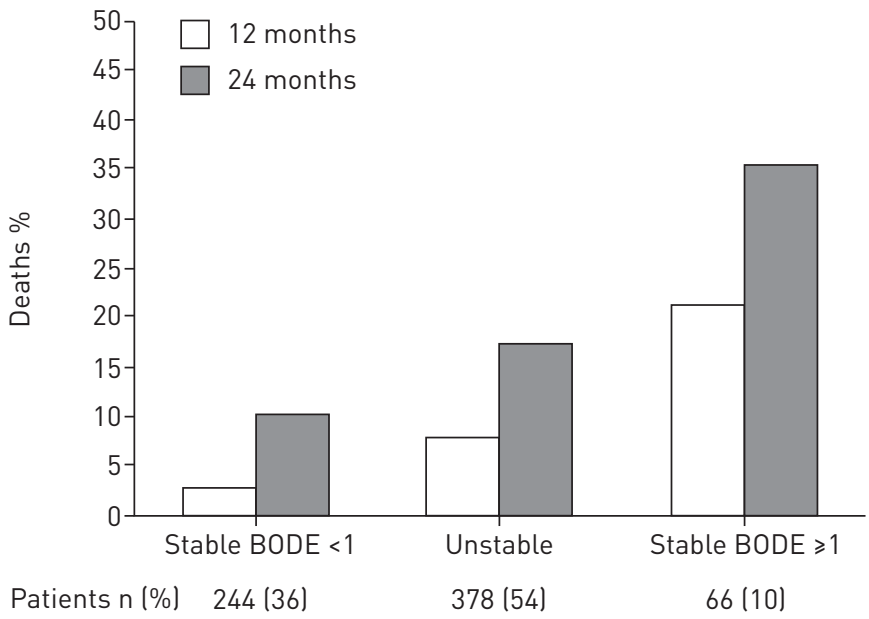

FIGURE 2 Association of BODE (body mass index, airflow obstruction, dyspnoea, exercise capacity) index 2year longitudinal pattern with risk of death at 12 and 24 months $(\mathrm{p}<0.001)$.

\section{Longitudinal patterns and mortality}

The longitudinal observation of the pattern over 2 years (three measurements) was sufficient to determine an impact on outcome. The 12- and 24-months mortality for BODE and its components are shown in table 3. The numbers of deaths for these periods were 51 and 115, respectively. The BODE index and $6 \mathrm{MWD}$ pattern of change, but not the FEV1 longitudinal pattern, were significant predictors of mortality (table 3 and fig. 2).

The BODE index pattern was a better predictor of 12- and 24-months mortality than 6MWD for both unstable and stable progression patterns. The risk ratio for the stable progression pattern for the BODE index was 7.40 (95\% CI 2.58-21.21) by 12 months and 4.50 (95\% CI 2.11-9.57) by 24 months.

TABLE 4 Baseline characteristics of the patients stratified by the longitudinal BODE lbody mass index, airflow obstruction, dyspnoea, exercise capacityl index patterns configured over 2 years

\begin{tabular}{|c|c|c|c|c|}
\hline Variable & Unstable & $\begin{array}{c}\text { Stable progressive } \\
\text { BODE } \geqslant 1\end{array}$ & $\begin{array}{c}\text { Stable nonprogressive } \\
\text { BODE }<1\end{array}$ & p-value \\
\hline Subjects & 372 & 66 & 242 & \\
\hline Male/female & $342 / 30$ & $61 / 5$ & $225 / 17$ & 0.905 \\
\hline Age years & $69 \pm 8$ & $68 \pm 9$ & $65 \pm 9$ & 0.005 \\
\hline Smoking pack-years & $65 \pm 25$ & $69 \pm 14$ & $63 \pm 28$ & 0.865 \\
\hline Active smoking \% & 29 & 29 & 28 & 0.955 \\
\hline $\mathrm{BMI} \mathbf{k g} \cdot \mathrm{m}^{-2}$ & $27 \pm 5.8$ & $26.5 \pm 5.4$ & $27.2 \pm 5.5$ & 0.600 \\
\hline FEV $1 \mathrm{~L}$ & $1.38 \pm 0.52$ & $1.39 \pm 0.53$ & $1.47 \pm 0.61$ & 0.119 \\
\hline FEV $1 \%$ & $46 \pm 16$ & $45 \pm 15$ & $47 \pm 18$ & 0.553 \\
\hline $\mathrm{PaO}_{2} \mathrm{mmHg}$ & $72.2 \pm 11.9$ & $69.8 \pm 12.8$ & $73.8(11.1)$ & 0.035 \\
\hline FVC $\%$ & $74 \pm 20$ & $80 \pm 21$ & $74(20)$ & 0.200 \\
\hline 6MWD m & $362 \pm 123$ & $349 \pm 101$ & $394(134)$ & 0.003 \\
\hline mMRC dyspnoea score & $2(0-4)$ & $2(0-4)$ & $2(0-4)$ & 0.351 \\
\hline BODE index & $4(1-8)$ & $4(1-7)$ & $3(0-9)$ & 0.103 \\
\hline IC/TLC ratio & $0.29 \pm 0.12$ & $0.33 \pm 0.16$ & $0.30(0.11)$ & 0.370 \\
\hline Kco \% & $58 \pm 23$ & $55 \pm 16$ & $63(22)$ & 0.109 \\
\hline Charlson index & $4(2-9)$ & $5(2-9)$ & $4(1-8)$ & 0.001 \\
\hline Hospitalisation per patient per year & $0.25 \pm 0.02$ & $0.27 \pm 0.06$ & $0.14(0.02)$ & 0.007 \\
\hline Inhaled anticholinergic \% & 68 & 72 & 68 & 0.965 \\
\hline Inhaled $\beta_{2}$-agonist $\%$ & 94 & 97 & 89 & 0.393 \\
\hline Inhaled corticosteroid \% & 62 & 62 & 63 & 0.970 \\
\hline SGRQ & $49 \pm 20$ & $50 \pm 19$ & $43 \pm 21$ & 0.035 \\
\hline
\end{tabular}

Data are presented as $n$, mean \pm SD or median (5-95th percentile), unless otherwise stated. BMI: body mass index; FEV1: forced expiratory volume in $1 \mathrm{~s} ; \mathrm{PaO}_{2}$ : arterial oxygen tension; FVC: forced vital capacity; 6MWD: 6-min walk distance; mMRC: modified Medical Research Council; IC: inspiratory capacity; TLC: total lung capacity; KCO: transfer coefficient of the lung for carbon monoxide; SGRQ: St George's Respiratory Questionnaire. 
TABLE 5 Relative risk of mortality in patients with chronic obstructive pulmonary disease using multiple logistic binary regression modelling ${ }^{\#}$

\begin{tabular}{lcr} 
& Relative risk (95\% Cl) & p-value \\
\hline Stable nonprogressive BODE index pattern & Reference & 0.325 \\
Unstable BODE index pattern & $1.549(0.648-3.701)$ & $<0.001$ \\
Stable progressive BODE index pattern & $6.750(2.324-19.608)$ & 0.448 \\
Progressive 6MWD pattern & $1.773(0.403-7.793)$ & 0.001 \\
Charlson index & $1.286(1.101-1.502)$ & 0.003 \\
$\mathrm{Hospitalisations}_{\mathbf{P a O}_{2}}$ & $2.626(1.387-4.971)$ & 0.271 \\
$\mathrm{SGRQ}$ & $0.984(0.956-1.013)$ & 0.281 \\
\hline
\end{tabular}

BODE: body mass index, airflow obstruction, dyspnoea, exercise capacity; 6MWD: 6-min walk distance; $P \mathrm{aO}_{2}$ : arterial oxygen tension; SGRQ: St George's Respiratory Questionnaire. " : with constant using backward stepwise method and Wald's criteria/five iterations including BODE index pattern, 6MWD pattern, Charlson index, hospitalisations, age and $\mathrm{PaO}_{2}$.

The baseline characteristics of the BODE index of the cohort according to the longitudinal patterns are shown in table 4. There were no differences in smoking habits, FEV1, BODE index, medications and other parameters among the three longitudinal pattern groups.

Adjusting the logistic model by the baseline differences showed that the BODE index longitudinal pattern remained an important and independent predictor of mortality at 12 and 24 months (table 5).

\section{Discussion}

This study of patients with COPD attending pulmonary clinics has several findings. First, during a prolonged period of follow-up we observed a high intra-individual variability over time in FEV1, which is smaller for the BODE index. Secondly, the BODE index, but not the FEV1 longitudinal pattern, is useful because its annual change over a period of 2 years (one baseline measurement and two yearly measurements) has the best capacity to predict the risk of death in the following 12 and 24 months. Finally, these results suggest a practical approach for the frequency, timing and interpretation of longitudinal measures in patients with COPD based on an important outcome such as mortality.

This study provides insight into the interpretation of variations occurring in the individual domains characterising COPD progression in clinical practice. Most studies assessing changes in lung function did not address individual patient variability since they evaluated FEV1 changes using mean group value [22-24]. Over the past 2 years, three observational studies have shown that the annual rate of FEV1 decline is variable and that the progression of COPD differs depending of the variable used to characterise it [2-4].

\section{Longitudinal pattern change}

As originally described by FLETCHer and PeTo [6], not all patients manifest a monotonous change in FEV1 over time. However, it was not until the study by GUERRA et al. [7] that attempts were made to quantify this variability and relate it to outcomes. These authors noticed that patients with restrictive disease, whose lung function changed significantly in $50 \%$ of the yearly visits, had increased mortality compared with patients with lesser variability. We applied a more stringent threshold by defining an unstable pattern if the variability was significant in $66 \%$ of the measures, and evaluated the variation using two thresholds: $\geqslant 40 \mathrm{~mL} \cdot$ year $^{-1}$ and $\geqslant 100 \mathrm{~mL} \cdot$ year $^{-1}$. We observed that a large proportion of patients with COPD manifest an unstable pattern of change, that is to say there is a large variability in FEV1 at different visits. The proportion differs depending on the threshold used to define the variability (table 2). The proportion of patients was largest when a threshold of $40 \mathrm{~mL} \cdot \mathrm{year}^{-1}$ was used and, although it decreased if $100 \mathrm{~mL} \cdot \mathrm{year}^{-1}$ was selected, it still remained very large. The same is true if the results are expressed as a percentage of predicted value, with the lowest proportion seen if $6 \%$ versus $3 \%$ is used. In contrast to the findings by GUERRA et al. [7], who reported a higher mortality rate in restrictive patients with the inconsistent pattern (more variability), the pattern of change in FEV1 did not help predict outcome using all of the thresholds explored.

When variability is tested for BODE and its components, several findings are evident. First, using the threshold of 1 point per year measured over 2 years, a stable pattern (less variability) of BODE deterioration of 1 point per year is a marker of poor prognosis compared with patients with an unstable or a stable nonprogressive pattern $(<1$ point per year). Interestingly, the BODE index component with the highest contribution to its predictive power was the 6MWD. 
The relative stability of the dyspnoea score we report is consistent with four studies with longitudinal data of changes in dyspnoea [25-28]. Recently, and similarly to our findings, MAHLER et al. [28] observed that dyspnoea measured using the mMRC dyspnoea scale did not increase significantly when measured every 6 months over 2 years. To our knowledge there are no longitudinal studies about the evolution of BMI in patients with COPD and its relationship to outcome. Our results showed that the potential impact of BMI change on predicting mortality is very low.

The pattern of change of the $6 \mathrm{MWD}$ did predict mortality with a stable decrease of $\geqslant 50 \mathrm{~m} \cdot \mathrm{year}^{-1}$ being associated with increased risk of death. However, the "consistent" pattern of deterioration of the BODE index remained a better predictor in the multivariate analysis (table 4). We believe that the integrative characteristic of the BODE index better helped to smooth all the changes of the individual variables, and in this way improve outcome prediction. Indeed, longitudinal changes in the BODE index with specific therapeutic interventions were associated with survival among COPD patients [29, 30].

The COPD guidelines recommend that symptoms be monitored with measurement of spirometry to modify therapy, identify complications and avoid disease progression [1,9]. The GOLD strategy recommends adding the frequency of exacerbations, the perception of dyspnoea and comorbidities to assessment [1]. All guidelines offer little practical guidance to support this statement. In fact, the evidence is controversial. A Danish population study suggested that the new classification is able to predict exacerbation [31], but data from the same study and a pooled analysis in 11 Spanish cohorts [31, 32] showed that this new grading of patients with COPD compared to the old GOLD staging based on spirometry alone is worse at predicting mortality. In addition, the recommendations remain opinion based $[1,9]$. Our results support multidimensional assessment including the use of an exercise evaluation (in our case the $6 \mathrm{MWD}$ ), because a stable deterioration of $50 \mathrm{~m} \cdot \mathrm{year}^{-1}$ provides outcome information. Indeed, two studies evaluated the 6MWD change over time with similar results [33, 34].

In terms of when to measure the variables, our data suggests that at least three (one baseline and two yearly follow-up) assessments are necessary to define a reliable pattern. We believe that the integrative characteristic of the BODE index better smoothed all the changes of the individual variables and in this way improved outcome prediction. Based on the results, it may be advisable to perform the BODE index, since it provides a more accurate prediction of mortality.

Some limitations of the implementation of the 6MWD test in clinical practice have been related to the need of a corridor and the time consumed. This test has become routine in the evaluation of pulmonary hypertension and idiopathic pulmonary fibrosis [33], confirming the value of the test in specialised practices.

There are some limitations of our study. First, the BODE cohort is an observational study of patients attending pulmonary clinics and is not a general medical practice or population-based study. As we described previously, it is possible that in this setting there are more patients with a lower value of BODE index and the consistent nonprogressive pattern will be more frequent. Secondly, few females were included, and the findings reported here cannot be extended to that sex. Finally, our findings should be validated in other cohorts. However, the excellent characterisation of the patients in the cohort, the longitudinal followup and the use of mortality as an outcome are important advantages that outweigh some of the drawbacks.

In summary, we demonstrated a large individual variability over time in FEV1, which is smaller for the BODE index. Among the variables included in the BODE index only the stable deterioration of the 6MWD was predictive of mortality at 1 and 2 years. However, a consistent worsening of the multidimensional BODE index was even more powerful than the 6MWD in predicting outcome. Our findings confirm the limitations of the FEV1 alone and support the BODE index as a very useful tool to implement in the longitudinal approach to patients with COPD. More studies in different settings are needed to validate the proposed algorithm for the follow-up of patients with COPD.

\section{References}

Vestbo J, Hurd SS, Agustí AG, et al. Global strategy for the diagnosis, management and prevention of chronic obstructive pulmonary disease. GOLD executive summary. Am J Respir Crit Care Med 2013; 187: 347-365.

2 Vestbo J, Edwards LD, Scanlon PD, et al. Changes in forced expiratory volume in 1 second over time in COPD. N Engl J Med 2011; 365: 1184-1192.

3 Casanova C, de Torres JP, Aguirre-Jaíme A, et al. The progression of chronic obstructive pulmonary disease is heterogeneous: the experience of the BODE cohort. Am J Respir Crit Care Med 2011; 184: 1015-1021.

4 Nishimura M, Makita $\mathrm{H}$, Nagai K, et al. Annual change in pulmonary function and clinical phenotype in chronic obstructive pulmonary disease. Am J Respir Crit Care Med 2012; 185: 44-52.

Drummond MB, Hansel NN, Connett JE, et al. Spirometric predictors of lung function decline and mortality in early chronic obstructive pulmonary disease. Am J Respir Crit Care Med 2012; 185: 1301-1306.

Fletcher C, Peto R. The natural history of chronic airflow obstruction. BMJ 1977; 1: 1645-1648.

Guerra S, Sherrill DL, Venker C, et al. Morbidity and mortality associated with the restrictive spirometric pattern: a longitudinal study. Thorax 2010; 65: 499-504. 
Celli BR, Cote C, Marin JM, et al. The body-mass index, airflow obstruction, dyspnea, and exercise capacity index in chronic obstructive pulmonary disease. N Engl J Med 2004; 350: 1005-1012.

9 Celli BR, MacNee W, Agusti A, et al. Standards for the diagnosis and treatment of patients with COPD: a summary of the ATS/ERS position paper. Eur Respir J 2004; 23: 932-946.

10 Lung function testing: selection of reference values and interpretative strategies. Am Rev Respir Dis 1991; 144: $1202-1218$.

11 Macintyre N, Crapo RO, Viegi G, et al. Standardisation of the single-breath determination of carbon monoxide uptake in the lung. Eur Respir J 2005; 26: 720-735.

12 ATS Committee on Proficiency Standards for Clinical Pulmonary Function Laboratories. ATS statement: guidelines for the six-minute walk test. Am J Respir Crit Care Med 2002; 166: 111-117.

13 Mahler DA, Wells CK. Evaluation of clinical methods for rating dyspnea. Chest 1988; 93: 580-586.

14 Charlson M, Szatrowsky T, Peterson J, et al. Validation of a combined comorbidity index. J Clin Epidemiol 1994; 47: 1245-1251.

15 Donaldson GC, Seemungal TA, Patel IS, et al. Airway and systemic inflammation and decline in lung function in patients with COPD. Chest 2005; 128: 1995-2004.

16 Kohansal R, Martinez-Camblor P, Agustí A, et al. The natural history of chronic airflow obstruction revisited: an analysis of the Framingham offspring cohort. Am J Respir Crit Care Med 2009; 180: 3-10.

17 Herpel LB, Kanner RE, Lee SM, et al. Variability of spirometry in chronic obstructive pulmonary disease: results from two clinical trials. Am J Respir Crit Care Med 2006; 173: 1106-1113.

18 Sandford AG, Chagani T, Weir TD, et al. Susceptibility genes for rapid decline of lung function in the lung health study. Am J Respir Crit Care Med 2001; 163: 469-473.

19 Casanova C, Cote C, de Torres JP, et al. Inspiratory-to-total lung capacity ratio predicts mortality in patients with chronic obstructive pulmonary disease. Am J Respir Crit Care Med 2005; 171: 591-597.

20 Nishimura K, Izumi T, Tsukino M, et al. Dyspnea is a better predictor of 5-year survival than airway obstruction in patients with COPD. Chest 2002; 121: 1434-1440.

21 Casanova C, Cote C, Marín JM, et al. Distance and oxygen desaturation during the 6-min walk test as predictors of long-term mortality in patients with COPD. Chest 2008; 134: 746-752.

22 Anthonisen NR, Connett JE, Kiley JP, et al. Effects of smoking intervention and the use of an inhaled anticholinergic bronchodilator on the rate of decline of FEV1. JAMA 1994; 272: 1497-1505.

23 Celli BR, Thomas NE, Anderson JA, et al. Effect of pharmacotherapy on rate of decline of lung function in chronic obstructive pulmonary disease: results from the TORCH study. Am J Respir Crit Care Med 2008; 178: 332-338.

24 Tashkin DP, Celli B, Senn S, et al. A 4-year trial of tiotropium in chronic obstructive pulmonary disease. $N$ Engl J Med 2008; 359: 1543-1554.

25 Mahler DA, Tomlinson D, Olmstead EM, et al. Changes in dyspnea, health status, and lung function in chronic airway disease. Am J Respir Crit Care Med 1995; 151: 61-65.

26 Ries AL, Kaplan RM, Limberg TM, et al. Effects of pulmonary rehabilitation on physiologic and psychosocial outcomes in patients with chronic obstructive pulmonary disease. Ann Intern Med 1995; 122: 823-832.

27 Oga T, Nishimura K, Tsukino M, et al. Longitudinal deteriorations in patient reported outcomes in patients with COPD. Respir Med 2007; 101: 146-153.

28 Mahler DA, Ward J, Waterman LA, et al. Longitudinal changes in patient-reported dyspnea in patients with COPD. COPD 2012; 9: 522-527.

29 Cote CG, Celli BR. Pulmonary rehabilitation and the BODE index in COPD. Eur Respir J 2005; 26: 630-636.

30 Martinez FJ, Han MK, Andrei AC, et al. Longitudinal change in the BODE index predicts mortality in severe emphysema. Am J Respir Crit Care Med 2008; 178: 491-499.

31 Lange P, Marott JL, Vestbo J, et al. Prediction of the clinical course of chronic obstructive pulmonary disease, using the new GOLD classification: a study of the general population. Am J Respir Crit Care Med 2012; 186: 975-981.

32 Soriano J, Alfageme C, Almagro P, et al. Distribution and prognostic validity of the new Global Initiative for Chronic Obstructive Lung Disease grading classification. Chest 2013; 143: 694-702.

33 Casanova C, Cote CG, Marin JM, et al. The 6-min walking distance: long-term follow-up in patients with COPD. Eur Respir J 2007; 29: 535-540.

34 Spruit MA, Polkey MI, Celli B, et al. Predicting outcomes from 6-minute walk distance in chronic obstructive pulmonary disease. J Am Med Dir Assoc 2012; 13: 291-297. 